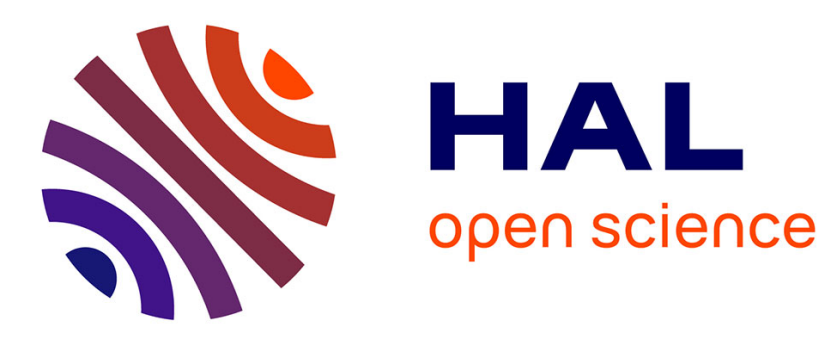

\title{
Characteristics of a surface wave produced discharge operating under standing wave conditions
}

\author{
Z. Rakem, P. Leprince, J. Marec
}

\section{To cite this version:}

Z. Rakem, P. Leprince, J. Marec. Characteristics of a surface wave produced discharge operating under standing wave conditions. Revue de Physique Appliquée, 1990, 25 (1), pp.125-130. 10.1051/rphysap:01990002501012500 . jpa-00246153

\section{HAL Id: jpa-00246153 https://hal.science/jpa-00246153}

Submitted on 1 Jan 1990

HAL is a multi-disciplinary open access archive for the deposit and dissemination of scientific research documents, whether they are published or not. The documents may come from teaching and research institutions in France or abroad, or from public or private research centers.
L'archive ouverte pluridisciplinaire HAL, est destinée au dépôt et à la diffusion de documents scientifiques de niveau recherche, publiés ou non, émanant des établissements d'enseignement et de recherche français ou étrangers, des laboratoires publics ou privés. 


\title{
Characteristics of a surface wave produced discharge operating under standing wave conditions
}

\author{
Z. Rakem (*), P. Leprince and J. Marec \\ Laboratoire de Physique des Gaz et des Plasmas (**), Université Paris-Sud, 91405 Cedex France
}

(Reçu le 19 mai 1989, révisé le 16 août 1989, accepté le 14 septembre 1989)

\begin{abstract}
Résumé. - On présente un dispositif permettant d'obtenir des décharges à partir d'un système d'ondes de surface stationnaires (SWD) et on le compare aux décharges du même type en ondes progressives (TWD). Toutes les caractéristiques de la décharge (densité et température des neutres, intensités des raies du plasma...) sont modulées. La période spatiale de la modulation est identique à celle du système d'ondes stationnaires. En supposant que les conditions d'entretien des décharges TWD et SWD sont les mêmes, on trouve que la densité électronique est modulée autour d'un profil plat.
\end{abstract}

\begin{abstract}
A device for standing surface wave discharges (SWD) is presented and compared to classical travelling surface wave discharges (TWD). All discharge characteristics (neutral temperature and density, intensities of plasma lines...) are modulated with the same spatial period as the electromagnetic field. Assuming the discharge sustaining conditions of TWD are still valid, it is found that the electron density is modulated around a plateau-like density profile.
\end{abstract}

\section{Introduction.}

Surface wave produced in argon gas at low pressure have been extensively studied [1-10]. These discharges sustained by a travelling wave are overdense and exhibit an axial electron density gradient as shown in figure 1 . The plasma length is depending on the microwave input power and the electron density decreases from the excitation zone to the end of the plasma column where it reaches a critical value. Below this value, the surface wave can no longer propagate.

As this density gradient can be a disadvantage for some app ications aser structures or instance, we have built a new discharge structure in order to obtain a plateau-like density profile. It is based on the following idea : if we prevent the wave propagates to the critical density point, it will be reflected and if we choose the reflection point at a distance short enough from the excitation zone, we shall

(*) Present Address : Haut Commissariat à la recherche-Alger-Algérie.

$(* *)$ Associated with C.N.R.S.

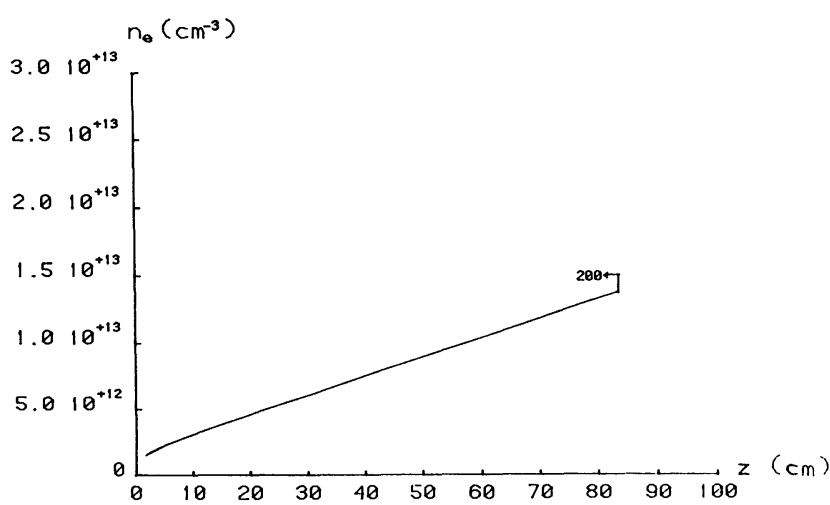

1g. . - Typical gradient of the electron density in Travelling Wave Discharge (TWD), $F=2.45 \mathrm{GHz}$, $P_{\text {in }}=200 \mathrm{~W}, p=1$ Torr, Tube diameter $=5 \mathrm{~mm} . z=0$, end of the plasma column, $\leftarrow$ gap position.

obtain a standing wave pattern which exhibits a plateau-like density as expected.

A standing surface wave system using two discharges produced by coaxial cavities has been previously studied by Rogers et al. [11]. They found that the variations of the electric $E_{r}$ and magnetic 
$H_{\varphi}$ fields surrounding the discharge were related to the « visual » (i.e. total) light emitted by the plasma.

This paper briefly describes a device to obtain such a standing wave pattern and then reports on the determination of its plasma characteristics and presents the relations between $E_{r}, H_{\varphi}$, the electronic and neutral densities, the neutral temperature and the line intensities.

\section{Standing wave device.}

The standing wave device is shown in figure 2. Microwave power $(0-1 \mathrm{~kW})$ is delivered by a $2.45 \mathrm{GHz}$ microwave generator into a rectangular wave guide operating on the $\mathrm{TE}_{01}$ mode. This power is coupled to the discharge via a surfaguide structure [12] with the coupling efficiency better than $80 \%$ on the azimuthal $m=0$ mode.

Surfaguide and a short-circuit (denoted 1 on the drawing) have been assembled to prevent the plasma expansion towards the left part of the arrangement. Another short-circuit (denoted 2 on the drawing) is movable along the discharge tube. It also prevents the plasma expansion towards the right part of the tube as the surface wave is reflected on it. So, by moving the short-circuit 2 , we are able to change the plasma length, hence the plasma characteristics.

Discharge tube is a quartz tube which the inner and outer diameters are respectively 5 and $10 \mathrm{~mm}$. Preliminary experiments have shown, under typical conditions (pressure $\sim 1$ Torr, microwave power $\sim 100 \mathrm{~W}$ ), that the intensities of lines emitted by the plasma are modulated around a constant mean value along the discharge as soon as the distance between the excitation gap and short-circuit 2 is about $21 \mathrm{~cm}$. Therefore, this length has been fixed and both parts of the structure (surfaguide and short-circuit 2) have been assembled by a metallic cylinder (15 $\mathrm{mm}$ diameter) coaxially surrounding the discharge tube. Nevertheless, the discharge length can be changed over a few centimers by moving the plunger inside the short-circuit 2. The metallic cylinder on the one hand prevents any electromagnetic radiation towards apparatus and also prevents the propagation of guide modes or higher order plasma modes, on the other hand it provides a reference wall for electromagnetic measurements and computations. This cylinder is slotted in order to enable electrical and optical diagnostics along the discharge by moving either an antenna or an optic fiber connected to a monochromator.

\section{Experiments.}

Experimental conditions were the following: without flow discharge in argon gas at low pressure ( $p \sim$ 0.5-3 Torr), input microwave power $\sim 50-300 \mathrm{~W}$. In order to determine the wave pattern and the discharge characteristics, we have to determine, the electromagnetic field distribution inside and outside the plasma, the neutral temperature, the neutral density and the electron density along the plasma column. Electrical and optical diagnostics have been used. In both cases, the probe (either an antenna or an optical arrangement) is fixed on a movable set carried on a motorized Microcontrole MT 160 platine.

3.1 EleCtrical MEASUREMENTS. - Discharge is generated by the azimuthally symmetric $m=0$ mode which the electromagnetic components are the radial and axial electric fields $\left(E_{r}\right.$ and $\left.E_{z}\right)$ and the azimuthal magnetic field $\left(H_{\varphi}\right)$. Therefore the antenna is either a small bared wire of a coaxial cable or a small loop. The former picks up a signal which the intensity is proportional to $\left|E_{r}\right|^{2}$, the latter picks up a signal which the intensity is proportional to $\left|H_{\varphi}\right|^{2}$.

3.2 OptiCAl Diagnostics. - A very simple two lenses arrangement (Fig. 3) is focused on the plasma whereas the light beam coming from the optical system is refocused on the front plane of an optic

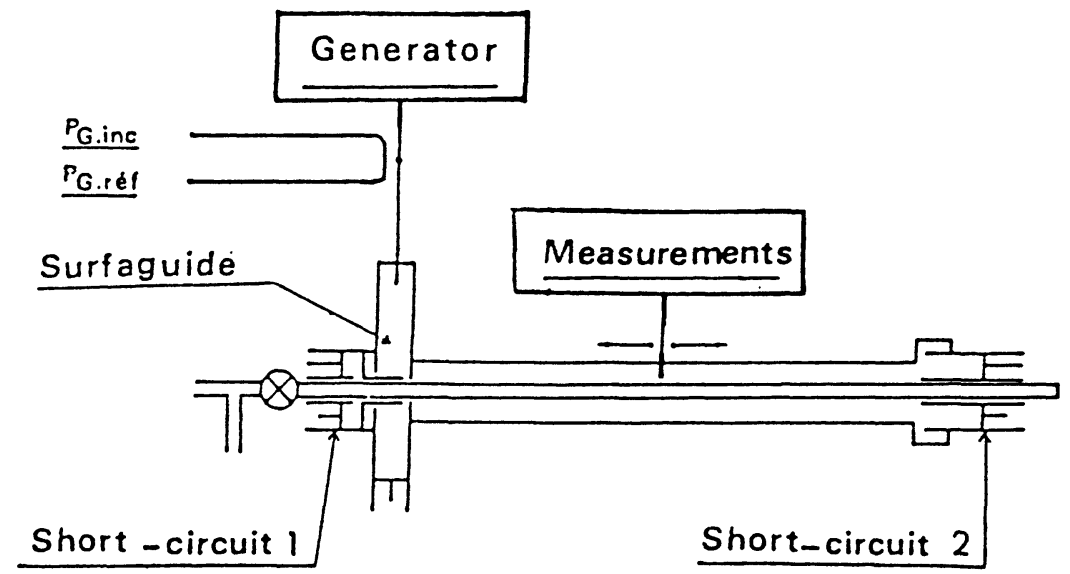

Fig. 2. - Standing wave device. 


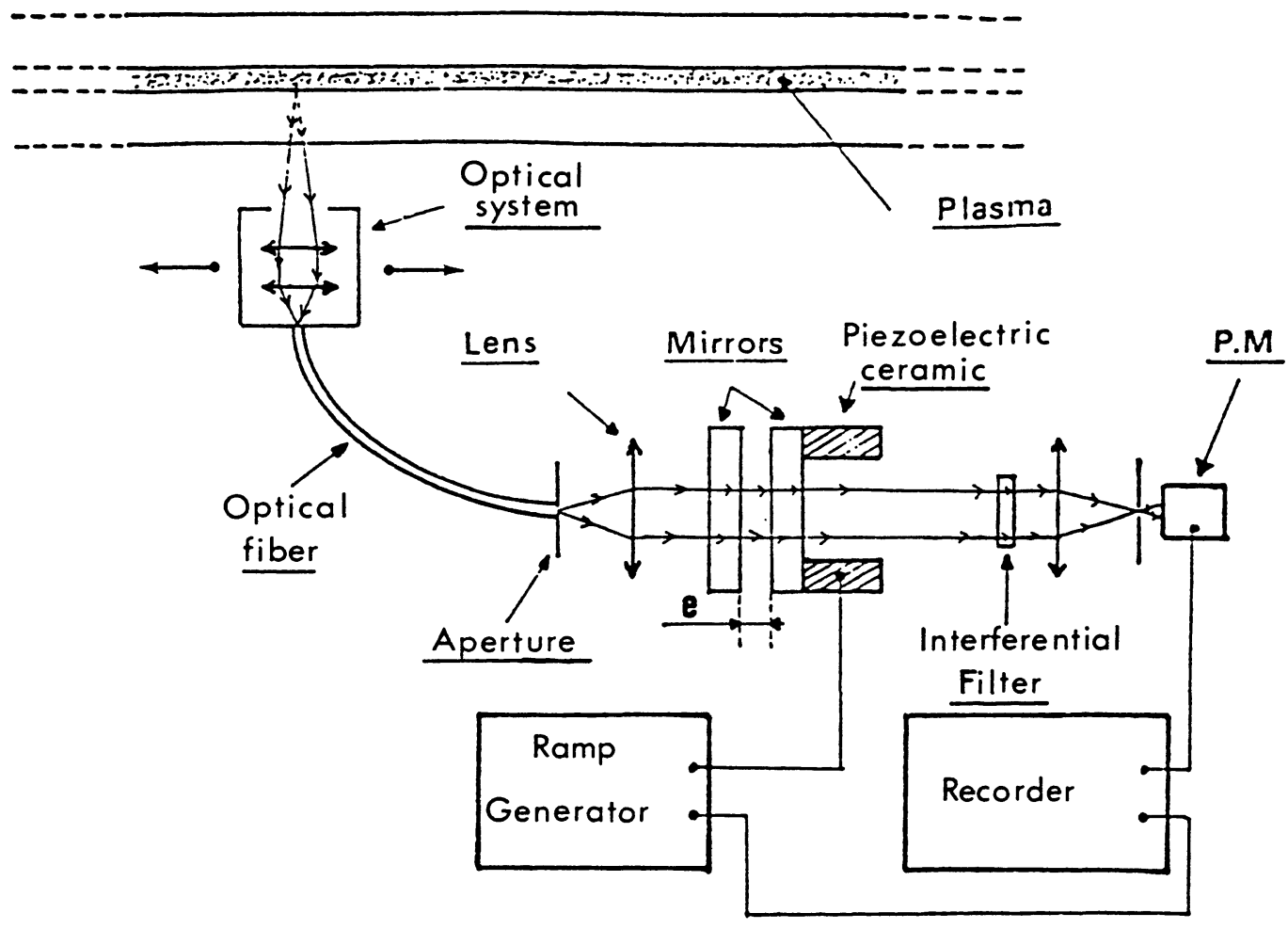

Fig. 3. - Optical arrangement for diagnostics.

fiber which the diameter is $200 \mu \mathrm{m}$. Then, the light is transmitted either to a Perot-Fabry interferometer or to a monochromator.

3.2.1 Line width measurements. - Experimental device is shown in figure 3 . The rear face of the optic fiber is located in the focal plane of a lens which gives a parallel beam first falling on the Perot-Fabry mirrors, then on an interferential filter. Finally, the beam is refocused on the photomultiplier slit.

In order to obtain the neutrals temperature $T_{0}$, the $696.5 \mathrm{~nm}$ neutral argon line has been chosen. Plasma is an optically thin medium for that line. Thus, the absorption broadening is negligible and the only line broadening to take into account is the Doppler one. Then, the neutral temperature is obtained from the formula :

$$
T_{0} \sim 4.2 \times 10^{4} \frac{\Delta \sigma_{\mathrm{D}}}{\Delta \sigma}{ }^{2}
$$

for a mean distance $e=1.5 \mathrm{~cm}$ between the mirrors and $\lambda=696.5 \mathrm{~nm} . \Delta \sigma_{\mathrm{D}}$ is the line half width and $\Delta \sigma_{\mathrm{i}}$ is the free spectral width. Under our experimental conditions, the accuracy on the temperature determination is estimated to $10 \%$.

3.2.2 Measurements of line intensities. - It has been already shown that argon surface wave discharges are governed by ambipolar diffusion under similar experimental conditions [3]. Hence we can assume the excitation processes involved in Surface Wave
Discharges (further denoted SWD) are the same as in Traveling Wave Discharges (further denoted TWD) because they only depend on the conditions of plasma generation. Furthermore, the condition $\nu \ll \omega$ (where $\nu$ is the electron-neutral collision frequency and $\omega$ is the microwave excitation pulsation) is satisfied. We know, under these conditions, that intensities of ArI and ArII lines obey the following semi-empirical laws [6] :

$$
\begin{gathered}
I_{\mathrm{ArI}}=\alpha_{\mathrm{I}} n_{\mathrm{e}} n_{0}\left\langle E_{\mathrm{P}}\right\rangle^{3} \\
I_{\mathrm{ArII}}=\alpha_{\mathrm{II}} n_{\mathrm{e}}^{3}\left\langle E_{\mathrm{P}}\right\rangle^{4.5} .
\end{gathered}
$$

Where $\alpha_{\mathrm{I}}$ and $\alpha_{\mathrm{II}}$ are constants and $\left\langle E_{\mathrm{P}}\right\rangle$ is the electric field inside the plasma, averaged over the tube section. From $n_{0}$ and relative intensity variations, we can deduce $n_{\mathrm{e}}$ and $\left\langle E_{\mathrm{P}}\right\rangle$ variations along the discharge [13]. Accuracy on these variations is estimated to $30 \%$.

or $\mathrm{t}$ at 1agnostic, the rear face of the optic fiber is connected to the photomultiplier by a monochromator Jobin-Yvon HR1000.

\section{Results.}

A typical set of experimental results obtained is shown in figure 4. Argon pressure is 0.5 Torr and microwave input power is $70 \mathrm{~W}$. We only present the results over $10 \mathrm{~cm}$ but they are the same over the all discharge length. It can be seen that the field components, the neutrals temperature and the line 


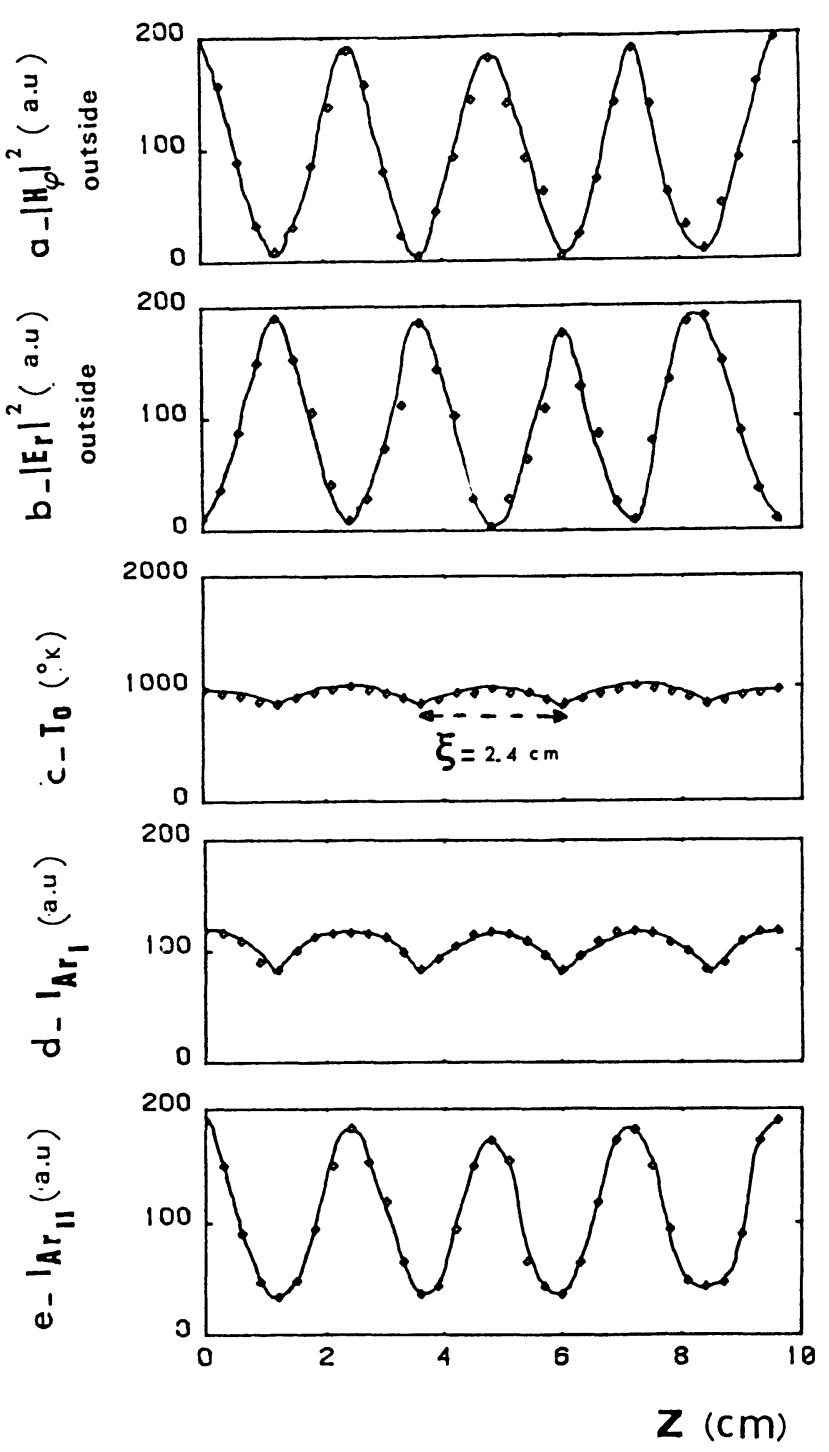

Fig. 4. - Typical measures - Tube 5-10-15 mm $p=0.5$ Torr $-P_{\text {in }}=70$ W. a) $\left|H_{\varphi}\right|^{2}$, b) $\left|E_{r}\right|^{2}$, c) $T_{0}$, d) $I_{\text {Arl }}$, e) $I_{\text {Arll }}$.

intensities exhibit a spatial modulation which the spatial period $\xi$ is the same. We find $\xi \simeq 2.4 \mathrm{~cm}$.

From relations (2) and (3), we can deduce the electron density and the plasma field variations

$$
n_{\mathrm{c}} \text { is proportional to }\left(\frac{n_{0}}{I_{\text {ArI }}}\right)\left(I_{\text {ArII }}\right)^{1 / 1.5}
$$

$\left\langle E_{\mathrm{P}}\right\rangle$ is proportional to $\left(\frac{I_{\mathrm{ArI}}}{n_{0}}\right)^{3 / 4.5} \times$

$$
\times\left(I_{\text {ArII }}\right)^{-1 / 4.5} \text {. }
$$

As there is no flow in the discharge, the pressure is homogeneous, the neutral density can be determined from the equation of state of ideal gases

$$
p=n_{0} k T_{0}
$$

where $k$ is the Boltzmann constant.
Figure 5 shows the variations of neutral and electronic densities and those of the plasma field. From the idea of a standing wave pattern in our device, based on the discharge creation by two surface waves propagating in opposite directions, we
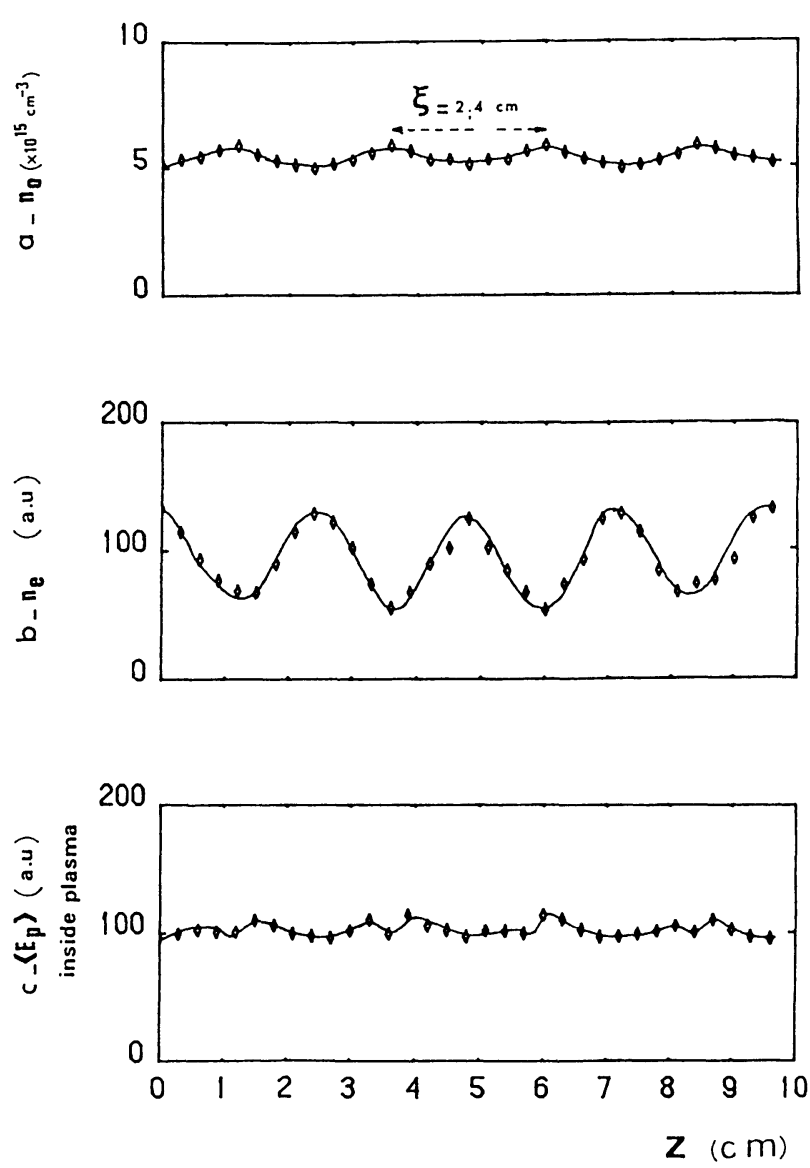

Fig. 5. - Variations along the structure of a) neutral density, b) electronic density, c) Plasma field. Same conditions as in figure 4.

expect this pattern has a spatial period equal to a half wavelength $\lambda / 2$. Therefore, the $\xi$ spatial period we have observed over the fields (cf. Fig. 4) leads to the relation

$$
\xi=\frac{\lambda}{2}
$$

Then, from the dispersion equation and the experimental conditions, following a method we already have detailed in previous papers $[3,6]$, we are able to determine the axial distribution of the absolute value of electron density. Figure 6 gives the results under the above experimental conditions. The electron density is modulated around a mean value $n_{\mathrm{c} 0}=5.1 \times 10^{12} \mathrm{~cm}^{-3}$. To obtain the same value in TWD, we approximately need three times the SWD power, i.e., about $200 \mathrm{~W}$. 


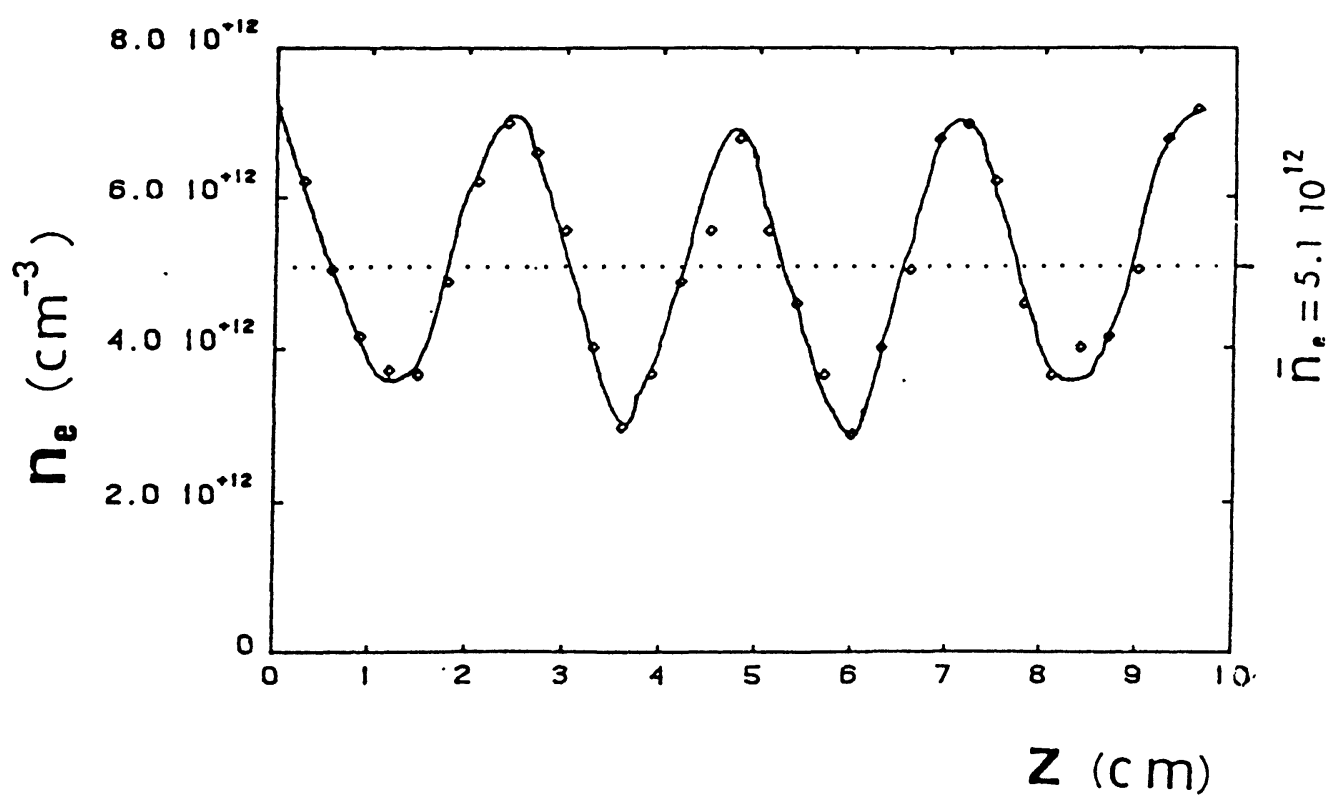

Fig. 6. - Axial distribution of the electron density. Same conditions as in figures 4, 5.

\section{Discussion.}

For all modulations axially observed, it is possible to find the oscillations of every quantity around a mean value. Therefore modulations of all quantities can be characterized both by the phase relations they have between them and their modulation rate defined as :

$$
\zeta=\frac{G_{\max }-G_{\min }}{G_{\max }+G_{\min }}
$$

where $G_{\max }$ and $G_{\min }$ are respectively the maximum and minimum values of the $G$ quantity.

Under our experimental conditions, we finally find the modulation rates shown in table $\mathrm{I}$.

Table I.

\begin{tabular}{|c|c|c|c|c|c|c|c|c|}
\hline$G$ & $I_{\text {ArI }}$ & $I_{\text {ArI }}$ & $T_{0}$ & $n_{0}$ & $n_{\mathrm{e}}$ & $\left\langle E_{\mathrm{p}}\right\rangle$ & $\left|E_{r}\right|^{2}$ & $\left|H_{\varphi}\right|^{2}$ \\
\hline$\zeta \%$ & 20 & 70 & 10 & 10 & 35 & 5 & 87 & 90 \\
\hline
\end{tabular}

Modulation rates of $T_{0}, n_{0}$ and $\left\langle E_{\mathrm{P}}\right\rangle$ are very weak. This feature means that the corresponding quantities are quite constant, particularly the electric field inside the plasma. The later result is important because it suggests the $\left\langle E_{\mathrm{P}}\right\rangle$ field is a discharge characteristic as in the TWD case implying the collision frequency $\nu$ and $\theta$, the mean power needed for the maintaining of an electron in the discharge $[7,8]$ also have weak variations along the discharge.

Phase relations are presented in table II with regards to the electron density.
Table II.

\begin{tabular}{|c|c|c|c|c|}
\hline$G$ & $I_{\text {ArI }} I_{\text {ArII }} T_{0}$ & $n_{0}\left\langle E_{\mathrm{p}}\right\rangle\left|E_{r}\right|^{2}$ & $\left|H_{\varphi}\right|^{2}$ & $n_{\mathrm{e}}$ \\
\hline phase & $\begin{array}{c}\text { no phase } \\
\text { different }\end{array}$ & $\begin{array}{c}\text { opposite } \\
\text { phases }\end{array}$ & $\begin{array}{c}\text { no phase } \\
\text { difference }\end{array}$ & $\begin{array}{c}\text { reference } \\
\text { phase }\end{array}$ \\
\hline
\end{tabular}

We finally find all quantities are either in opposite phase or have no phase difference.

\section{Conclusion.}

Plasma created by standing wave device is axially modulated but, as it was expected, the mean axial profile of the electron density is a plateau-like one. Further, we have found the electric field $\left\langle E_{\mathrm{P}}\right\rangle$ inside the plasma is nearly constant. Hence, as in the TWD case, $\left\langle E_{\mathrm{P}}\right\rangle$ and the two parameters $\nu$ and $\theta$ are also discharge characteristics. This result means the equilibrium conditions for a discharge maintaining in us, 1 is jus 1 ie 0 use the TWD modelling, particularly to determine the electron density from a wavelength $\lambda$ which is twice the spatially observed wavelength $\xi$. Nevertheless, the SWD itself has to be modelized. Our feeling is such a model should be based both on the TWD properties and the propagation conditions of a surface wave in a modulated medium. Such a modelling is now in progress and will be presented in a further paper.

As a proof of the efficiency of standing wave device with regards to the ion laser ability, a small 
laser structure based on it has been built. An argonhelium mixture $(1: 1)$ generated at $2.45 \mathrm{GHz}$ provides the $488 \mathrm{~nm}$ laser line with an efficiency of about $5 \times 10^{-5}$ whereas no laser effect was obtained under the same experimental conditions in a travelling wave discharge [14].

\section{References}

[1] Zakrzewski Z., Moisan M., Glaude V. M. M., BeAudry C. and Leprince P., Plasma Phys. 19 (1977) 77.

[2] Glaude V. M. M., Moisan M., Pantel R., LePRINCE P. and MAREC J., J. Appl. Phys. 51 (1980) 5693.

[3] Chaker M., Nghiem P., Bloyet E., Leprince P. and Marec J., J. Phys. Lett. France 43 (1982) L71.

[4] Ferreira C. M., J. Phys. D : Appl. Phys. 14 (1981) 1811.

[5] Ferreira C. M., J. Phys. D : Appl. Phys. 16 (1983) 1673.

[6] Chaker M. and Moisan M., J. Appl. Phys. 57 (1985) 91.

[7] Boisse-Laporte C., Granier A., Dervisevic E., Leprince P. and MARec J., J. Phys. D : Appl. Phys. 20 (1987) 197.

[8] Granier A., Boisse-Laporte C., Leprince P., Marec J. and Nghiem P., J. Phys. D : Appl. Phys. 20 (1987) 204.
[9] Boisse-Laporte C., Granier A., Bloyet E., LePrince P. and Marec J., J. Appl. Phys. 61 (1987) 1740.

[10] Darchicourt R., Pasquier S., Boisse-Laporte C., Leprince P. and Marec J., J. Phys. D : Appl. Phys. 21 (1988) 293.

[11] Rogers J., Asmussen J., IEEE trans. Plasma Sci. PS 10 (1982) 11.

[12] Moisan M., Beaudry C., Bertrand L., Bloyet E., Gagne J. M., Leprince P., Marec J., Mitchel G., RicARD A. and ZAKRZEWSKI Z., IEE Conf. Publ. 143 (1976) 382.

[13] RAKem Z., TundaK T., LePrinCe P. and MAREC J., XVIIth Int. Conf on Phenomena in Ionized Gases, 682, Budapest (1985).

[14] Rakem Z., Leprince P., Marec J. and SaAda S., 39th Gaseous Electronics Conf., Madison (1986). 